\title{
Personal Sales and e-Business
}

\author{
Assoc. Prof. PhD Penka Goranova \\ D. A. Tsenov Academy of Economics - Svishtov, Bulgaria \\ p.goranova@uni-svishtov.bg
}

\begin{abstract}
Sales can be defined as ways of shaping each transaction that implements products, services and ideas, and transferring ownership rights from buyer's sales representatives. A sale is limited to doing business itself and delivering products, services, and ideas to buyers' sales representatives. Sales perform economic, social and psychological functions. On the one hand, they are aimed at monetizing the organization that performs the respective business, and on the other hand, they realize the buyers' incomes to acquire the necessary products for production and consumer purposes. At both times, sales are at the heart of the economic turnaround in economic life and the path to successful economic growth and social development. The purpose of the report is to present the main aspects of personal sales, the benefits of e-business and the role of e-commerce in contemporary business. New needs are generated through online sales and can actively influence consumer behavior.
\end{abstract}

Keywords: Marketing, Personal Selling, Marketing Mix, e-business, e-commerce, consumer behavior.

JEL Code: M30, M31; doi:10.36997/IJUSV-ESS/2019.8.2.163

\section{Въведение}

Дейностите при продажбите влияят съществено върху поведението на клиентите, като го насочват в благоприятна за организацията насока на развитие. Основните съображения тук се свеждат до формирането и стимулирането на психическите процеси у купувачите. Така се постига състояние на благотворно отношение и положителна оценка към работата на фирмата, нейните продукти, цени, пазари и други.

За разлика от производството, при продажбите страни на процеса са хора с тяхната икономическа, социална, демографска, психологическа и лична характеристика. Затова при продажбите „трябва да се развият всички знания, умения и навици на търговските представители, за да се спечели доверието на купувачите и да се приемат предлаганите продукти“" (Banchev, 2006, pp. 10).

Личните продажби са инструмент за маркетингови комуникации, който се използва за увеличаване на обема на продажбите непосредствено в хода на личен контакт. „Личните продажби предполагат устно представяне на продукта от страна на продавача с цел продажба“" (Stefanov, 2018, pp. 37).

Влиянието на личните продажби е пряко - на практика самото съществуване на търговските представители зависи от сключването на сделки. "Персонални продажби са устно представяне в разговор с един или повече потенциални купувачи, с цел осъществяване на продажба"(Kotler, 2000, pp. 209). По този начин е налице средство за установяване на планирани взаимовръзки с купувача и непосредствено извършване на пласментни операции. Следователно, това е процес на междуличностна комуникация, при която фирмата в лицето на своите търговски представители открива и задоволява нуждите на купувачите, което води до взаимна дългосрочна изгода за двете страни.

\section{1. Сыщностни аспекти на личните продажби}

С личните продажби тьрговските агенти на бизнес организациите целят увеличаване на продажбите и изграждане на взаимоотношения с клиентите (Kotler \& Armstrong, 2010). Необходимостта от лични продажби се увеличива поради повишаващата се конкуренция в повечето бизнес сфери, желанието за разширяването на пазарния дял, промените във вкусовете на клиентите и технологиите, увеличаването на взаимоотношенията с клиентите и обема на продажбите на бизнес органиизацията. 
Сред основните предимства на личните продажби се открояват:

$>$ Възможност за подбор на аудиторията, както и по-висока възможност за контрол върху реакциите на аудиторията.

$>$ Пряк контакт с потребителите и незабавна обратна връзка.

$>$ Силен стимулиращ ефект.

$>$ Възможност за даване на комплексна информация и отговаряне на възраженията.

$>$ Гъвкавост на съобщението - посланията могат много лесно да бъдат модифицирани според аудиторията, за разлика от рекламата.

По същество личната продажба е пряка комуникация между продавачите и потенциалните клиенти, обикновено лично, но тя също може да се осъществи по телефона, пощата, интернет и др. Тя служи като комуникационен мост между бизнес организацията и целевата аудитория. Той е ефективен, защото позволява пряка двупосочна комуникация между купувача и продавача. Това дава на бизнес организацията много по-големи възможности за проучване на нуждите на техните потребители и по-голяма гъвкавост на предложенията и представянето им, за да отговори на тези нужди (Perreault \& McCarthy, 2000; Doyle \& Stern, 2006).

Според Котльр в днешната свръх конкурентна бизнес среда не може да се разглежда продажба само като обикновена търговска сделка. Търговските представители трябва да познават желанията и нуждите на свойте клиенти по-добре дори от тях самите и да настройват своите бизнес стратегии спрямо клиентите си (Kotler \& Armstrong, 2010)

Личната продажба е най-скъпата форма на промоция, което е и един от основните ѝ недостатъци. По същество тя включва изграждането на взаимоотношения чрез комуникация с цел сключване на сделка за продажба. Изследването на Weitz \& Castleberry (2004) определят личната продажба като междуличностен процес, при който продавачьт се опитва да открие и задоволи нуждите на купувачите по взаимно дългосрочен начин, подходящ и за двете страни. Така личната продажба се утвърждава като междуличностна комуникация, свързана със стоките и услугите. „Комуникацията е основна дейност за търговския представител по време на лична продажба. Това е социална ситуация, включваща двама души в комуникационнен обмен“" (Engel \& Kollat, 2011).

Трябва да отбележим, че личните продажби много рядко се използват като самостоятелно средство за маркетингова комуникация, в повечето случаи подпомагат останалите средства на ИМК. Те се осъществява чрез презентация на стоката в реално време пред потенциален купувач. Изборът на типа и методите на лични продажби в една организация зависи от няколко фактора, които определят комбинацията им с връзките с обществеността, рекламата и насьрчаването на продажбите.

Ролята на личните продажби в стратегическия маркетинг е с тенденция към повишаване, а по-рутинните задачи все повече се поемат от неличните средства за комуникация. “Личната продажба дава големи възможности в мениджърската кариера за растеж, професионална свобода и независимост, професионална предизвикателство и високи възнаграждения“ (Goranova, 2013, pp. 142). Още повече се извършва персонално адресиране на продуктите, а скъпоструващите предполагат и промоции, които се очакват от клиентите. "Колкото е по-високо е нивото на внедряване на логистичния мениджмънт в управленската йерархия на предприятието, толкова по-силно е влиянието на изпълняваните управленски функции“ (Perkov, 2013, pp. 609), но важно значение за ефикасна работа при личните продажби има организацията на тяхното осъществяване, която може да се извърши по място на създаване на продуктите от организациите-производители, по местонамиране на търговски представителите или по местоживеене (месторабота, местосъбиране) на купувачите. Стимулиращият ефект се засилва, когато личните продажби се осъществяват поблизо до месторазположението на купувачите. 


\section{2. Основни пазарни предложения}

Успехът от комуникацията изразяваща се в продажба зависи от това доколко и двете страни постигат общо разбиране, което дава възможност за взаимно постигане на цели чрез социално взаимодействие (Kotler, 2013). Освен това, Weitz \& Castleberry (2004) заявява, че ролята на търговския представител е да ангажира и събира информация за потенциалния клиент, да разработва стратегия за продажби, базирана на тази информация, да предаде съобщение, като прилага търговските стратегии на бизнес организацията, да оценява въздействието на тези съобщения и прави необходимите корекции в своето предложение за да постигне продажба. Днес компаниите „разполагат с неограничен брой възможности, за да предлагат различни пазарни предложения“ (Kotler, 2015, pp. 234). Те могат да бъдат класифицирани по следния начин:

$>$ цифрови и физически предложения;

$>$ нематериални и материални предложения;

$>$ функционални и интелигентни предложения;

$>$ контейнери и съдържание.

Пьрва група, „цифрови и физически предложения“ (Kotler, 2015, pp. 122) представляват най-вече информационни продукти и услуги като финансови услуги, новинарски услуги, развлекателни и мултимедийни продукти и услуги за дистрибуция на софтуер. Възходът на интернет даде началото на иновативни цифрови продукти като онлайн рекламата, онлайн игрите, стаите за чат и удостоверителните услуги. Втора група, материални действия и материални средства разделят предложенията на четири групи въ3 основа на техния получател: съзнанието на хората (например консултантски и информационни услуги), телата на хората (например ресторанти и пътнически транспорт), материални активи (например експресни пощенски услуги и ремонт на автомобили) и нематериални активи (например застраховане и банкиране). В повечето случаи потребителите почти не се интересуват от самия краен резултат или самото преживяване. Затова много компании вече се стремят да диференцират нематериалните дейности, които създават желаното от клиентите преживяване. Трета група, функционални и интелигентните предложения са свързани с технологиите и са неизменна част от продуктите и тяхното обкръжение, за да ги направят „по-умни”. На индустриалния пазар компаниите масово използват интернет, за да доставят стойност, като заменят, модернизират или прекратяват рутинни ръчни дейности. Четвърта група, разглежда на контейнери (уреди като прожекционни апарати или принтери) и на съдържание - информация, носеща добавена стойност (като видеоклипове и софтуер). При своята маркетингова дейност стопанският мениджър постоянно е в търсене на „маркетингов микс”, който да донесе печалба за всеки продукт или група продукти, които той трябва да продаде.

\section{3. Характеристики на електронния бизнес}

Фактът, че все повече фирми от съответните браншове и с различен мащаб си прокарват път в Интернет води до усъвършенстване на сделките в икономическото пространство. Разбира се това създава и нови финансови опасности и рискове за пазарните агенти (предложители и потребители). Проверка за ефективността на сделките в киберсредата са получените плащания, а за успешния маркетингов план на фирмите критерий са постъпилите от клиентите поръчки за доставка на продукти и услуги. „Повишаването на нивото на културата и образованието всеки ден променят взискателността и очакванията на потребителите“(Ilieva, 2018, pp. 266). Всичко това се извършва на основата на съвременните информационни технологии, ново технологично оборудване и съвременни програмни решения.

Дейностите, свързани с електронен бизнес винаги са подплатени с необходимост от различни форми на разплащане - в брой, с чек, с кредитна или дебитна карта, които могат да 
бъдат реални или виртуални. Потребителите в мрежата трябва да разполагат с широк набор от плащания и да разчитат на сигурност за техните реални и виртуални пари.

За да запазят конкурентните си позиции и равнището на продажби, фирмите предлагат широк спектьр от начини за плащане в мрежата - от наложен платеж до онлайн платежно нареждане до банка.

Електронният бизнес има няколко сфери на проявление:

- използване на Интернет като средство за осъществяване на маркетинг - тук се включват промотиране на Web-сайт, дейности за увеличаване броя на посетителите и за повторното им привличане, анализиране на журналите за достъп и др.;

- организиране на разплащателни дейности - осъществяване на различни начини на плащане, защита на Web-сайтовете, продажби по интернет, плащания с реални и виртуални пари и др.;

- доставка на електронни и реални продукти - свързва се с четене, прехвърляне на файлове и тяхната защита, предоставяне на информация в мрежата, публикуване на данни за бюджет, публикуване на документи в мрежата и др..

Бизнесът в мрежата може да се извършва от два типа субекти, а именно:

\section{* Бизнес, извършван от фирми}

Много компании развиват своя бизнес в интернет като път към усъвършенстване на потребителските услуги и повишаване нивото на продажби. През 1995 г. самолетната компания „Alaska Airlines” предлага за пръв път на своите клиенти възможност да получат информация за полетите, да резервират и закупят билети по Интернет като резултат от предварително маркетингово проучване, което показва силен интерес към такава услуга у клиентите на фирмата. Сайтьт на компанията предлага две опции за онлайн плащане на билетите - с кредитна карта или по предварително открита сметка на името на потребителя.

Ниските разходи при стартиране на бизнес в мрежата привличат хиляди малки и големи компании с една единствена цел - да осъществяват сделки по възможно най-лесен и бърз начин, с висока степен на сигурност за своите клиенти. Предимството е, че със своя сайт малките компании изглеждат също така добре представени в киберпространството, както и транснационалните корпорации.

\section{* Бизнес, извършван от потребители}

Много често електронният бизнес може да се извършва от дома чрез посещаване на определени сайтове или четене на електронна поща. Това са случаи, когато дадена фирма или агенция иска да популяризира своята дейност, като плаща на рекламна къща да рекламира дейността й на сайтовете си за реклама. Рекламната къща от своя страна получава доходи и обикновено е с висок рейтинг следствие на ускорената посещаемост от страна на потребителите, като за това ги стимулира с определена сума за техните посещения на сайтовете ѝ.

От гледна точка на потребителите, предимствата на този бизнес са, че обикновено се работи на принципа на точкуването (,получаваш X броя точки, които ти носят У пари"), не заема място от екрана на монитора, не изисква регистрация в много сайтове, носи реални приходи. Обикновено се изисква само посещаване на сайта на рекламната къща, кликване върху банерите и четене на писма, които се изпращат в e-mail.

Положителните страни при извършването на такъв тип бизнес, са и следните:

1. Не се влага начален капитал, изисква се само наличие на валиден имейл и регистрация в сайта на рекламната агенция.

2. Няма определено работно време, нито норма за броя на посещенията в сайта.

3. Получава се равнопоставено заплащане според заработката.

4. Липсва обвързване с фирмата-поръчител и с рекламната агенция.

5. Дейността носи бонуси.

Всяка рекламна къща подава различен брой писма за четене или банери дневно. 
Сайтовете предлагат поне два начина за осъществяване на бизнес от потребителите. Основният е чрез писма - след като получи писмото в своята електронна поща, потребителят трябва да кликне върху предложената препратка. Вторият начин е чрез кликване върху банери.

Недостатъците на този бизнес са, че е възможен провал на самата рекламна агенция, възможността агенцията да се окаже фалшива (да не изплаща бонусите) или по някаква причина да се получи срив на системата.

\section{4. Анализ на продажбената дейност от електронен магазин на Фирма Дикар Консулт}

Фирма Дикар Консулт води съвременна рекламна политика. Практически фирмата се рекламира, чрез съвременни и нови методи и не използва традиционните медии, като телевизия и радио. По-конкретно тя се възползва от безплатните платформи онлайн и платени в лицето на Google Ads. Във виртуалното пространство фирмата подържа седем сайта и ги рекламира, чрез платформата Google Ads. Рекламните кампании се проследяват и координират от отдел маркетинг. Те се стремят всеки ден да привличат огромен по обем, тясно таргетиран трафик с различна дисплейната мрежа към рекламираните сайтове.

В резултата от водените кампании фирмата може да се похвали с постигнатите добри резултати от 2018 г., „ськратените разходите за реклама с 30\% за 2019 г, а същевременно увеличение броя на клиентите си със $17 \%$ "1.

Анкетната карта стартира на 01.04.2019 г. и приключи на 05.05.2019 г. Тя се получава във всеки потвърждаващ имейл за завършена поръчка от сайта. В края на периода е попълнена от 100 респондента, но за съжаление е завършена от 44. За 47,7\% от анкетираните клиенти оценяват като важен фактор консултацията със служител на фирмата за потвърждаване на поръчката ${ }^{2}$. Същевременно 40,9\% от клиентите е оценяват като „Много важен” този разговор, но има и клиенти, за които разговора не представлява важен критерии или предимство - $11,4 \%$.

Като най-голямо предимство на фирма „Дикар Консулт” ООД е „Бърза доставки” $20,5 \%$, а на второ място клиентите поставят като важна причини „Добро обслужване” и „Коректност” - 13,6\%. Това е явен признак за желанието на клиентите за бърза реакция и изпълнение на всяка една допълнителна опция от страна на фирмата. На трето място се посочва „Възможността за кандидатстване на лизинг” и „Голям асортимент от техника” 9,1. Интерес представляват факторите с 6,8\%: „Утвърдена марка „Дикар Консулт”,, „Безплатна доставка”, „Оторизиран доставчик на световни марки”. По-малко влияние оказват факторите: „Добро консултиране по телефона”- 4,5\% и с по 2,3\% се изтькват факторите „Дизайн и цена”, „Бърза реакция на сервиза”. Необходимо е да се отбележи, че $2,3 \%$ от анкетираните посочват липсата на предимство, а същевременно 2,3\% не са отговорили на поставения въпрос - таблица 1.

Важно за дейността на всяка фирма е наличието на конкуренти на пазара. Точно в този контекст анкетата показва, че $60 \%$ от клиентите пазаруват от конкурентни фирми. Според анкетираните клиенти основни конкуренти не превъзхождат с „Нищо”-36,4 \%, което води до извода, че те са пазарували от тях, защото са попаднали първо в техния сайт и не са предпочели тях въз основа на конкретно предимство. Единствения значим процент е в полза на „по-ниска цена” с 6,8 \%, други показатели с еднакъв процент са „допълнителни функции” и,,Бърза доставка" с 4,5 \% - таблица 2.

\footnotetext{
${ }^{1}$ По данни от вътрешни отчети на фирмата

${ }^{2}$ Клиентите са били попитани „Важно ли е за Вас потвърждението и разговора със служител на фирмата за Вашата поръчка?“
} 
Таблица 1. Кое е най-голямото предимство при пазаруването от електронния магазина на Дикар Консулт?

\begin{tabular}{|l|c|c|}
\hline & $\begin{array}{c}\text { Брой } \\
\text { отговорили } \\
\text { респонденти }\end{array}$ & Проценти \\
\hline Без отговор & 1 & 2,3 \\
\hline Няма предимство & 1 & 2,3 \\
\hline Дизай и цена & 1 & 2,3 \\
\hline $\begin{array}{l}\text { Възможност за } \\
\text { кандидатстване на лизинг }\end{array}$ & 4 & 9,1 \\
\hline Бързо обслужване & 6 & 13,6 \\
\hline $\begin{array}{l}\text { Утвьрдена марка „Дикар } \\
\text { Консулт” }\end{array}$ & 3 & 6,8 \\
\hline Голям асортимент от техника & 4 & 9,1 \\
\hline Бърза доставка & 9 & 20,5 \\
\hline Бърза реакция на сервиза & 1 & 2,3 \\
\hline Коректност & 6 & 13,6 \\
\hline $\begin{array}{l}\text { Добро консултиране по } \\
\text { телефона }\end{array}$ & 2 & 4,5 \\
\hline Безплатна доствка & 3 & 6,8 \\
\hline $\begin{array}{l}\text { Оторизиран доставчик на } \\
\text { световни марки }\end{array}$ & 3 & 6,8 \\
\hline \multicolumn{1}{|c|}{ Общо: } & $\mathbf{4 4}$ & $\mathbf{1 0 0 , 0}$ \\
\hline
\end{tabular}

Таблица 2. С какво конкурентните фирми превъзхождат Дикар Консулт?

\begin{tabular}{|l|l|l|}
\hline & $\begin{array}{c}\text { Брой } \\
\text { отговорили } \\
\text { респонденти }\end{array}$ & Проценти \\
\hline Без отговор & 13 & 29,5 \\
\hline С нищо & 16 & 36,4 \\
\hline По-голям асортимент & 1 & 2,3 \\
\hline По-добро качество & 1 & 2,3 \\
\hline Допълнителни функции & 2 & 4,5 \\
\hline По-ниска цена & 3 & 6,8 \\
\hline По-добра консултация & 1 & 2,3 \\
\hline Бърза доставка & 2 & 4,5 \\
\hline Големи отстьпки за количества & 1 & 2,3 \\
\hline Лесна поръчка & 1 & 2,3 \\
\hline Допълнтелни подарьци & 1 & 2,3 \\
\hline $\begin{array}{l}\text { Те имат продукти, които ние } \\
\text { предлагаме }\end{array}$ & 1 & 2,3 \\
\hline Безплатна доставка & 1 & 2,3 \\
\hline Общо: & $\mathbf{4 4}$ & $\mathbf{1 0 0 , 0}$ \\
\hline
\end{tabular}

Логично е след като има стремеж за удовлетворяване на клиентите по отношение на продуктовата гама, компанията да се стреми и към увеличаване на продажбите, които се реализират. Това води до въпроса „По какъв начин очаквате фирма Дикар Консулт ООД да 
Ви стимулира при продажбите?”. На първо място анкетираните поставят с 22,7\% „Игри”. Второ място се заема от „Допълнителни отстъпки” с 9,1\%. На трето място клиентите поставят следните стимули за продажби с 6,8\% „Награди”, „Възможност за отложено заплащане". Като фактори които биха повлияли на продажбите с 4,5\% се изтькват от клиентите - „Бонус /допълнителе консуматив/”, „Бонуси, подаръчни материали”, „По-големи отстъпки при пазаруване на фирми”, „С благотворителни награди”, „Други”. И тук има клиенти не върнали обратен отговорна въпроса - 18,2\% - таблица 3.

Таблица 3. По какъв начин очаквате фирма Дикар Консулт да Ви стимулира при продажбите

\begin{tabular}{|c|c|c|}
\hline Стимулиране & $\begin{array}{l}\text { Брой отговорили } \\
\text { респонденти }\end{array}$ & Проценти \\
\hline Без отговор & 8 & 18,2 \\
\hline Бонус /допълнителе консуматив/ & 2 & 4,5 \\
\hline Бонуси, подаръчни материали & 2 & 4,5 \\
\hline Намаляване цената на стоката & 1 & 2,3 \\
\hline Награди & 3 & 6,8 \\
\hline Подаръци & 1 & 2,3 \\
\hline Допълнителни отстьпки & 4 & 9,1 \\
\hline $\begin{array}{llll}\begin{array}{l}\text { Още отстьпка } \\
\text { количества }\end{array} & \text { при } & \text { големи } \\
\end{array}$ & 2 & 4,5 \\
\hline Тупане на точки & 1 & 2,3 \\
\hline $\begin{array}{l}\text { По-големи отстьпки } \\
\text { пазаруване на фирми }\end{array}$ & 2 & 4,5 \\
\hline $\begin{array}{lcc}\text { Възможност } & \text { за } & \text { отложено } \\
\text { заплащане } & & \\
\end{array}$ & 3 & 6,8 \\
\hline С промоции & 1 & 2,3 \\
\hline С благотворителни награди & 2 & 4,5 \\
\hline Игри & 10 & 22,7 \\
\hline Други & 2 & 4,5 \\
\hline Общо & 44 & $\mathbf{1 0 0 , 0}$ \\
\hline
\end{tabular}

Доброто партньорство се основава на качественото обслужване на клиентите. Тук обратна информация се получава от въпроса "Имали ли сте проблеми с обслужването и реализацията на Вашата порьчка?". Показателен е фактора, че 52,3\% от клиентите посочват като отговор „Не никога” и с $34,1 \%$ е отговорьт „Не си спомням”. На трето място се посочват с 6,8\% „Да веднъж или два пъти”. На въпроса без отговор са 4,5\%. На следващия въпрос относно характера на появилите с е проблеми, клиентите с а посочили „Проблеми с логистиката" с 4,5 \%. Което води до изводите с доставката и забавяне на куриерската служба.

\section{Заключение}

Примерьт с проведеното изследване и кампания в социална мрежа показват стремежът към пълно разбиране на поведението на потребителите и факторите, които го определят. Чрез това познание се управлява маркетинговия микс на фирмата - при създаването на правилните реклами, разработването на планове и стратегии за съответните рекламирани марки.

Основните цели на фирмата са свързани с: преврьщане в силен бранд и развиване на своите онлайн магазини; улесняване на клиентите си в електроните си поръчки и удовлетворяване на техните изисквания. Резултатите от подобно изследване могат да дадат 
отговор на това как да увеличим оборота и да реализираме по-голяма посещаемост на сайта Дикар Консулт. Фирмата трябва да засили своето социално присъствие социалните мрежи и то не само в Facebook, а да се присъедини и към Twitter, YouTybe, Agronet, Linkedin и др.

В заключение можем да кажем, че фирма Дикар Консулт е една съвременна фирма на българския пазар, която се интересува от своите потребителите, вслушва в техния глас и се стреми да отговори на техните потребности. Тя се стреми да предлага иновативни решения за рекламираните от нея световни марки, което е допълнително условие за бъдещия ѝ успех и висока конкурентоспособност.

\section{References}

1. Banchev, P. 2006, Upravlenie na prodazhbite. Tsenov, Svistov. (in Bulgarian)

2. Doyle, P. \& Stern, P. 2006, Marketing management and strategy, Pearson Education Limited, Harlow.

3. Engel, B. \& Kollat, G. 2011, Consumer Behavior. Hinsdale Illions: The Dry Press Reliable Publishers.

4. Goranova, P. 2013, Teoria na potrebitelskoto powedenie, Tsenov, Svishtov. (in Bulgarian)

5. Ilieva, L.,2018, Research on the Distribution of ISO 9001 among Bulgarian Enterprises, International Scientific and Practical Conference "Business Development Opportunities Economic, Management and Social Dimensions", tom 1, Svishtov AI

6. Kotler, P. \& Armstrong. G. 2010, Principles of marketing, 13th ed, Pearson Publishers.

7. Kotler, P. 2000, Upravlenie na marketinga, tom 2, Grafema, Sofia. (in Bulgarian)

8. Kotler, P. 2013, Marketing Management, 14th ed, Prentice Hall, New Jersey.

9. Kotler, P., Maesincee, S. \&. Jain, Dipak C. 2015, Marketingovi hodove. Nov podhod kam vazmozhnostite za pochalba, rastezh I obnovyavane, Iztok-Zapad, Sofia. (in Bulgarian)

10. Perkov, V. 2013, 'Logisticheniyat menidzhmant: Teoritichni problem i perspektivi', Regionalni i globalni izmereniya na targoviyata, Nauka i Ikonomika, Varna, pp. 605-615. (in Bulgarian)

11. Perreault, W.D. \& McCarthy, E.J. 2000, Essentials of marketing: a global-managerial approach, 8th edition, Irwin/McGraw-Hill, Boston.

12. Stefanov, Ts. 2018, Pazarna strategia i izrazhdane na firmenata konkurentosposobnost v oblast Veliko Tarnovo, Faber, Veliko Tarnovo (in Bulgarian)

13. Weitz, B.A \& Castleberry, S.B. 2004, Selling: building partnerships, 5th ed, McGraw Hill, New York. 